$\xi=-1$

\title{
Probabilistic Analysis of Structures Under Snow Load
}

\author{
Vitaliy Severyn $^{1 *}$, Andrii Pashchenko ${ }^{2}$, Pavel Mytrofanov ${ }^{3}$ \\ ${ }^{1}$ Poltava National Technical Yuri Kondratyuk University, Ukraine \\ ${ }^{2}$ Poltava National Technical Yuri Kondratyuk University, Ukraine \\ ${ }^{3}$ Poltava National Technical Yuri Kondratyuk University, Ukraine \\ *Corresponding Author E-Mail: Vitalyseverin76@Gmail.Com
}

\begin{abstract}
The authors of the article present a model of snow load on the construction of buildings and structures for the territory of Ukraine. This model can be used for others countries of the world. Numeric probabilistic models of snow load have been worked out for PC. The digital snow load model was developed based on observations of many Ukrainian weather stations. This model is implemented as a software package in the programming language $\mathrm{C}++$. The results of snow load simulation can be used to assess the reliability of building structures. Finally, the implementation of this algorithm will allow to calculate the reliability of a number of existing designs. The received reliability forecasts will allow to reveal potentially dangerous types of building structures and to justify on their basis a proposal to improve Code calculations.
\end{abstract}

Keywords: numeric probabilistic models, probabilistic analysis, snow load.

\section{Introduction}

The changes of climatic conditions have been observed on the territory of Europe for the last 15-20 years [1]. Climate change does not avoid the Ukraine territory [2]. Recently, has changed character of snow load: precipitation becomes intense, but shortlived. In some cases, increase in a short period of snow load leads to building structures failure $[4,5,6]$. Extremely important to assess a reliability of existing buildings and identify potentially dangerous groups of structures. For this purpose, it is extremely important to obtain a snow load model taking into account all its features of a probabilistic nature. Also, extremely important to develop a general model for assessing a reliability of building structures under snow load influence.

\section{Numerical Probabilistic Model of Ground Snow Load}

An important task is to create a digital snow load model on the basis of statistics of observations at Ukraine weather stations. The process of snow load modeling is divided into three steps.

\subsection{First Step}

At the given step:

- a definition of statistical characteristics for the creation of a digital load model;

- $\quad$ study the stationarity of the snow load process;

- to establish the accuracy of the load model on the basis of the likelihood of the marginal limit being used;

- determined a density of distribution of the snow load function;

- a possibility of use the correlations theory; an optimal length for one implementation to obtain a specified accuracy of a process model.

The main source for statistical processing is the data of regular snow measurements at Ukraine weather stations. Snow load has the following features:

- $\quad$ according to the Ukraine norms, the time of regular snow cover collection (every 5 days);

- features of a quasi-stationary stochastic process, snow load with annual statistical characteristics [7];

- polynomial-exponential law of distribution of snow load [8]:

$$
f(x)=\exp \left[\sum_{k=0}^{T}\left(C_{k} x^{k}\right)\right],
$$

where $T$ is degree of the polynomial;

$C_{k}$ - factors of the polynomial $(k=0 \ldots T)$;

- described by expression a normalized correlation function $r(\tau)=\exp (-\alpha \tau)$,

where $\alpha$ is a parameter of normalized correlation function;

- for snow load simulation, received a following length of realization

$T_{W}=t_{E}-t_{S}$,

where $t_{E}$ and $t_{S}$ is accordingly mean date of the beginning also of the end of winter.

\subsection{Snow Load Simulation Algorithm and Creation a Numerical Model for PC}

For the adequacy of snow load simulating, the length of the implementation should be comparable with the life of the structures. The modeling is based on the transformation of a normal random process by nonlinear functions [9]. 
We write the integral and differential functions of the transformation of a normalized polynomial-exponential stationary stochastic process $\xi(t)$ with a normalized correlation function $r(\tau)$

$F\left(\gamma_{y}\right)=\int_{a_{L}}^{\gamma_{y}} \exp \left(C_{0}+C_{1} \gamma_{y}+C_{2} \gamma_{y}^{2}+C_{3} \gamma_{y}^{3}\right) d \gamma_{y}$,
$f\left(\gamma_{y}\right)=\exp \left(C_{0}+C_{1} \gamma_{y}+C_{2} \gamma_{y}^{2}+C_{3} \gamma_{y}^{3}\right)$,

where $a_{L}$ - a left border of distribution.

Transformation function:

$\gamma_{y}=f\left(\gamma_{x}\right)$

$\int_{a_{L}}^{\gamma_{y}} \exp \left(C_{0}+C_{1} \gamma_{y}+C_{2} \gamma_{y}^{2}+C_{3} \gamma_{y}^{3}\right) d \gamma_{y}=$

$=\frac{1}{\sqrt{2 \pi}} \int_{b_{L}}^{\gamma_{x}} \exp \left(-\frac{\gamma_{x}^{2}}{2}\right) d \gamma_{x}$

For equation (6) there is no analytical solution. So, we solve this equation numerically. To do this, the function of the normalized normal distribution density is replaced by the reduction function on the interval $\left[b_{L} ; b_{R}\right]$. For the limit of this interval, the probability of output $P_{b}$ is very small. It depends on the given accuracy of the calculations. For example, for value $b_{L}=-4.0$ $P_{b}=6.334 \cdot 10^{-5}$. For $b_{L}=-5.0$ value $P_{b}=5.733 \cdot 10^{-7}$. In the interval $\left[b_{L} ; b_{R}\right]$ we set values $\gamma_{x}$ by discrete. After, we shall receive the conforming values $\gamma_{y}$. In a tabular form we presented the function $\gamma_{y}=f\left(\gamma_{x}\right)$. The given parameter is determined using the method of least squares. Relation $\gamma_{y}=f\left(\gamma_{x}\right)$ we approximate by a function:

$\gamma_{y}=f\left(\gamma_{x}\right)=P_{0}+P_{1} \gamma_{x}+P_{2} \gamma_{x}^{2}+$

$+P_{3} \gamma_{x}^{3}+P_{4} \gamma_{x}^{4}+P_{5} \gamma_{x}^{5}$

where $P_{i}(i=0 \ldots 5)$ - polynomial factors, which are determined by the least squares method.

Simulation of a normalized polynomial-exponential stationary stochastic process $\xi(t)$ with a normalized correlation function $r(\tau)$ reduces to the formation of a discrete realization $\xi_{0}[n]$ of a normalized normal random process and their transformation by the formula:

$$
\begin{aligned}
& \xi\left(\gamma_{y}\right)=P_{0}+P_{1}\left[\xi_{0}\left(\gamma_{x}\right)\right]+P_{2}\left[\xi_{0}\left(\gamma_{x}\right)\right]^{2}+ \\
& +P_{3}\left[\xi_{0}\left(\gamma_{x}\right)\right]^{3}+P_{4}\left[\xi_{0}\left(\gamma_{x}\right)\right]^{4}+P_{5}\left[\xi_{0}\left(\gamma_{x}\right)\right]^{5},
\end{aligned}
$$

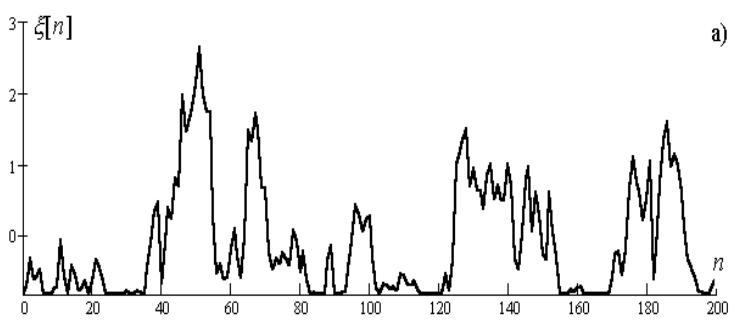

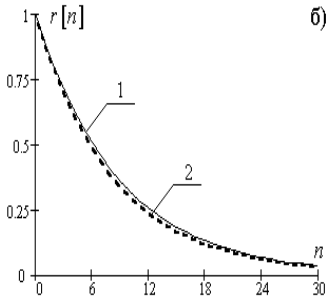

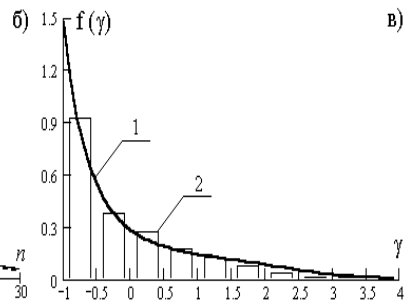

Fig. 1.: Digital process model of snow load: (a) process realization (b) normalized correlation process function (c) ordinates density function, 1 idealized data, 2 - experimental data.

The formula of numerical model of normalized normal stochastic process with normalized correlation function (2):

$$
\xi_{0(i)}\left[\gamma_{x}\right]=\sqrt{1-\rho^{2}} \gamma_{x}+\rho \xi_{0(i-1)}\left[\gamma_{x}\right]
$$

where $\xi_{0(i)}\left[\gamma_{x}\right]$ is ordinate of normalized normal stochastic process, $\rho=\exp \left(-\gamma^{*}\right), \gamma^{*}=\alpha \Delta t, \gamma_{x}$ - normally distributed random normalized value (expectation $\bar{X}=0$, standard $\hat{X}=1, \Delta t$ random step of load sampling (the interval between neighboring observations)

In Figure 1 are shown the results of simulation of a normalized polynomial-exponential stationary stochastic process.

\subsection{Digital Model of Snow Load for the Ukraine Territory According To the Data of Individual Weather Stations.}

This model is bases on formula that was introduced above. Factors to a polynomial (8) for the data of individual Ukraine weather stations are given in Table 1.

\begin{tabular}{|c|c|c|c|}
\hline \multirow[b]{2}{*}{$\begin{array}{l}\text { Factors of a trans- } \\
\text { formation func- } \\
\text { tion }\end{array}$} & \multicolumn{3}{|c|}{ Ukraine weather stations } \\
\hline & $\begin{array}{l}\text { Ivano- } \\
\text { Frankivsk } \\
\text { AMSG }\end{array}$ & Vinnitsa & Semenivka \\
\hline $\mathrm{P} 0$ & -0.02662 & -0.18393 & 0.21113 \\
\hline $\mathrm{P} 1$ & 1.18273 & 0.9563 & 1.01538 \\
\hline $\mathrm{P} 2$ & 0.15556 & 0.26648 & 0.1894 \\
\hline P3 & -0.1361 & -0.03891 & -0.02464 \\
\hline $\mathrm{P} 4$ & $-1.91 * 10-3$ & $-7.28 * 10-3$ & $-2.95 * 10-3$ \\
\hline P5 & $7.94 * 10-3$ & $1.64 * 10-3$ & $2.9 * 10-4$ \\
\hline
\end{tabular}

Table 1. Random process snow load factors for the polynomial numerical probabilistic models

The transition from a normalized form to a stochastic process with a real distribution of ordinates is carried out by the formula (10):

$\xi_{(i)}(x ; t)=\left[V \xi_{(i)}\left(\gamma_{y} ; t\right)+1\right] \bar{X}(t)$,

where $V$ - variation coefficient of snow load; $\bar{X}(t)$ - snow load mathematical expectation trend function. Random snow load value is always positive, i.e. $\xi(x ; t) \geq 0$. And therefore $\gamma_{y} \geq-(V)^{-1}$.

The results of the simulation are presented in Figure 2.

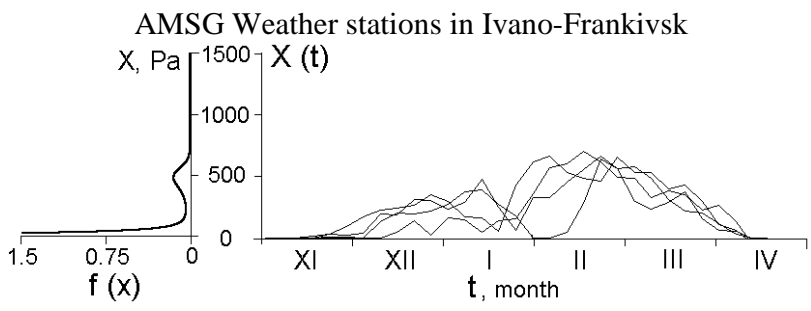




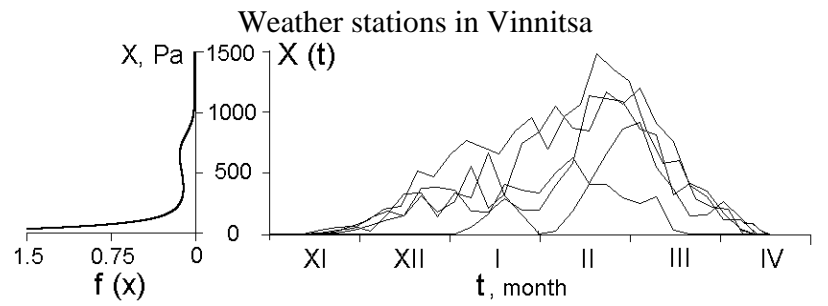

Weather stations in Semenivka

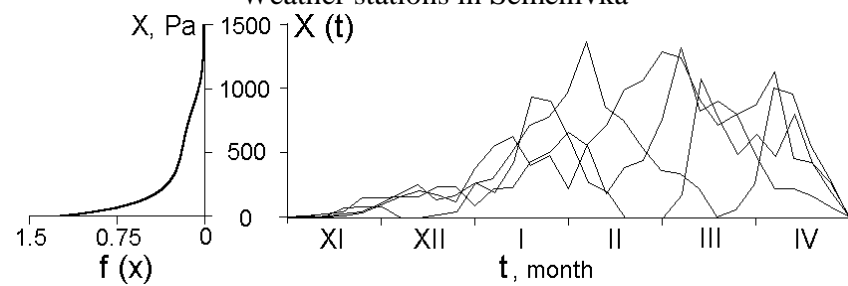

Fig. 2.: Annual realizations for Ukraine weather stations of quasistationary stochastic process for ground snow load.

\section{Evaluation of Building Structure Reliability Under Snow Load}

An important problem is reliability prediction of building structures calculated on strength and rigidity according to the requirements of the acting Codes of designing. Most of these structures made of elements covering structures: joists, purlins, roof rafters. A criterion for the reliability prediction - the probability of nonfailure of a structure for operation period serves. Two groups of reliability evaluation problem are divided depending on the area borders type of permissible conditions $\Omega$.

\subsection{Determining the Safety of the Building under the Random Boundary Region $\Omega-\tilde{\xi}$.}

Let us take into account a border $\tilde{\xi}$ that distributed under the law $f(\xi)$. In the normal stresses space determined the structure of a load carrying capacity. In the form of the stochastic process is presented the function of a load carrying capacity:

$$
Y(t)=\tilde{\xi}-u(t) \leq 0,
$$

where $u(t)$ is stochastic process of stresses in a building structure. Random values are the characteristics of constant load and strength of the building. Using a normal distribution law, we described their change. Function of the load-carrying capacity of the load $f(Y \bullet)$, we get as the difference between normal $f_{\xi}(\bullet)$ and polynomial-exponential distributions $f_{u}(\bullet)$.

$$
\left.f_{Y}(\gamma)=\sqrt{\frac{1+p^{2}}{2 \pi}} \int_{Z 1}^{Z 2}+C_{3} E^{3}\right) \exp \left(-0.5 Z^{2}\right) d Z
$$

where $E=-\gamma \sqrt{1+p^{2}}+Z p ; Z 1=D \gamma-1 /\left(V_{u} p\right)$;

$D=\left(\sqrt{1+p^{2}}\right) / p ; p=\hat{\xi} / \hat{u} ; \gamma=(Y-\bar{\xi}+\bar{u}) / \hat{Y} ;$

$\bar{\xi}, \bar{u}$ and $\hat{\xi}, \hat{u}$ - accordingly mathematical expectations and standards of distributions.

We determined parameter ${ }^{Z_{2}}$ using the method of selection outgoing from accuracy of the obtained results.

By the formula (13) is determined the probability of non-failure of a building member during time ${ }^{t}$ :

$P(t)=1-Q(t)$, where $Q(t)$ - a member failure probability [9].

$$
Q(t)=\frac{\omega_{e(Y)} t}{\beta_{\omega(Y)} \sqrt{2 \pi}} f_{Y}(\beta) ; \quad \beta=\frac{\bar{\xi}-\bar{u}}{\sqrt{\hat{\xi}^{2}+\hat{u}^{2}}},
$$

where ${ }^{\omega_{e(Y)}}$ and $\beta_{\omega(Y)}$ are effective frequency and structure complexity coefficient of stochastic process $Y(t)$. in Table 2 are given the $\beta_{\omega}$ values for snow load.

The portions of stress in building structures from operating constant (D1) and snow (D2) loads in common stress are determined using the formulae:

Table 2. Frequency features of snow load.

\begin{tabular}{|l|l|l|}
\hline $\begin{array}{l}\text { Weather } \\
\text { stations in } \\
\text { Ukraine }\end{array}$ & $\begin{array}{l}\text { Structure complexity } \\
\text { coefficient }\end{array}$ & $\begin{array}{l}\text { Characteristic maximum } \\
\gamma_{0}\end{array}$ \\
\hline $\begin{array}{l}\text { Ivano- } \\
\text { Frankivsk } \\
\text { AMSG }\end{array}$ & 2.677 & 3.097 \\
\hline Vinnitsa & 2.953 & 3.046 \\
\hline Semenivka & 3.280 & 3.197 \\
\hline
\end{tabular}

$$
D_{1}=\frac{k \gamma_{f(1)}}{k \gamma_{f(1)}+\mu \gamma_{f(2)}} ; D_{2}=\frac{\mu \gamma_{f(1)}}{k \gamma_{f(1)}+\mu \gamma_{f(2)}}
$$

where $k=q_{1}^{H} / s_{0}$ - an attitude of specified value of the uniformly distributed constant load $q_{1}^{H}$ ( $k P a$ ) to a value of weight of snow cover on $1 \mathrm{~m}^{2}$ (normative) of a horizontal ground surface $s_{0}$ ( $k P a) ; \mu$-coefficient of transition from the ground snow weight to the snow load on the roof structure; $\gamma_{f(1)}$ and $\gamma_{f(2)}$ - a reliability coefficient on snow loads and constant loads.

\subsection{Definition of Building Structure Reliability under the Constant Border of Area $\Omega-\tilde{\xi}=$ const .}

This group includes the problems of predicting the reliability of building elements based on the bending criterion. $t$

The assessment of the reliability of the elements is defined as the probability of not exceeding an accidental flexion $u(t)$ of the values of the permissible flexure $\xi$ in time $t$.

On formula (13) defined probability of survival of building element, where:

$$
Q(t) \approx N_{+}(t)=\frac{K_{w i n} f_{12}\left[\left(f_{u}-\bar{u}_{12}\right) / \hat{u}_{12}\right]}{\sqrt{1+\left(\hat{u}_{1} / \hat{u}_{2}\right)^{2}} f_{1}\left(\gamma_{0(2)}\right)},
$$

where $K_{\text {win }}=T_{\text {win }} / t$ - a snow load effect duration factor; $f_{u}$ - a permissible flexure of a girder determined according to normative documents; $\gamma_{0(2)}$ - maximum snow load characteristic. Responds to the term of repetition $t$. It received according to Table 2; $f_{12}(\bullet)$ - the total distribution of the snow load and constant load. Defined as the sum of the normal $f_{1}(\bullet)$ and polynomialexponential distributions $f_{2}(\bullet)$.

$$
\left.f_{12}(\gamma)=\left[\frac{\left(1+p^{2}\right)}{2 \pi}\right]^{\frac{1}{2}} \int_{Z 1}^{z 2}+C_{3} E^{3}\right) \exp \left(-0.5 Z^{2}\right) d Z,
$$

where $E=\gamma \sqrt{1+p^{2}}-Z p$; $Z 1=-1 / V_{u(2)} ; Z 2=D \gamma+1 /\left(V_{u(2)} p\right)$. 
The bending parts in a cover building member from D1 - operating constant and D2 - the load on the snow in common flexure is determined by the formula:

$D_{1}=k /(\mu+k) ; \quad D_{2}=\mu /(\mu+k)$.

The implementation of this algorithm will allow to calculate the reliability of a number of existing designs.

The received reliability forecasts will allow to reveal potentially dangerous types of building structures and justify on their basis a proposal to improve normative documents calculations.

\section{Conclusion}

As a result of the study of this problem, a numerical probabilistic model of snow load was developed, as well as a general method for forecasting the reliability of building structures under constant and snow loads. The obtained reliability forecasts will allow to identify potentially dangerous types of building structures and substantiate on their basis proposals on improving calculations under normative documents.

\section{References}

[1] Pietro Croce, Paolo Formichi, Filippo Landi " The snow load in Europe and the climate change", Climate Risk Management (2018), pp: $1-17$. https://doi.org/10.1016/j.crm.2018.03.001

[2] Yuriy Vynnykov, Olena Voskobiinyk, Maksym Kharchenko, Valentyn Marchenko, "Probabilistic analysis of deformed mode of engineering constructions' soil-cement grounds", MATEC Web Conf. Machine Modelling and Simulations 2017 (MMS 2017), Vol. 157, No. 05012, (2018), pp:1-8. https://doi.org/10.1051/matecconf/201711602038

[3] A. Haldar, S. Mahadevan, Reliability Assessment Using Stochastic Finite Elements Analysis, New York, 220 (2000)

[4] Nadezhda Chiganova "Reliability theory application for building structures reliability determination", MATEC Web Conf. Machine Modelling and Simulations 2017 (MMS 2017), Vol. 157, No. 05012, (2018), pp:1-7. https://doi.org/10.1051/matecconf/20168602009

[5] Derek L. Kozak, Abbie B. Liel "Reliability of steel roof structures under snow loads", Structural Safety, Volume 54, (2015), pp 46-56 https://doi.org/10.1016/j.strusafe.2015.02.004

[6] Ehsan Kianfar, Vahab Toufigh "Reliability analysis of rammed earth structures", Construction and Building Materials, Volume 127, 30 (2016), p.p. 884-895 https://doi.org/10.1016/j.conbuildmat.2016.10.052

[7] Guiliano Augusti, A. Baratta, F. Casciati, Probabilistic Methods in Structural Engineering, CRC Press, (1984), 582 p.

[8] S. F. Pichugin, Reliability of Steel Structures of Industrial Buildings [in Russian], Authors Abstract of the Doctor Degree Thesis (Tech. Sci.), Kiev (1994), 32 p.

[9] Pavlov A. B. Methodological fundamentals of the present-day building structures shape forming principles system / A. B. Pavlov, V. M. Fridkin // Architecture and construction. - M. : Academia, 2010. - No 1. - P. 70 - 73.

[10] Krasnobayev, V.A., Koshman, S.A. \& Mavrina, M.A. Cybern Syst Anal (2014) 50: 969. https://doi.org/10.1007/s10559-014-9688-3 